\title{
Antimicrobianos en la acuicultura
}

En el artículo: Resistencia a los antimicrobianos en Chile y el paradigma de Una Salud: manejando los riesgos para la salud pública humana y animal resultante del uso de antimicrobianos en la acuicultura del salmón y en medicina", de los autores Ana R. Millanao, Carolina Barrientos-Schaffeld, Claudio D. Siegel-Tike, Alexandra Tomova, Larisa Ivanova, Henry P. Godfrey, Humberto J. Dölz, Alejandro H. Buschmann y Felipe C. Cabello, publicado en Rev Chilena Infectol 2018; 35 (3): 299-303, en la página 299, columna derecha línea 6 , dice:

"También se ha demostrado repetidamente, en casi todos los países, tanto desarrollados como en desarrollo, que se utilizan muchos más antimicrobianos en la producción de animales para alimento humano y para otros usos veterinarios que en medicina humana ${ }^{2-5}$, uso veterinario que está ampliamente aceptado, aunque juega un papel importante en la aparición de resistencia antimicrobiana en patógenos animales y humanos ${ }^{2,5}$,

Debe decir:

"También se ha demostrado repetidamente, en casi todos los países, tanto desarrollados como en desarrollo, que se utilizan muchos más antimicrobianos en la producción de animales para alimento humano y para otros usos veterinarios que en medicina humana ${ }^{2-5}$; uso veterinario que está ampliamente aceptado juega un papel importante en la aparición de resistencia antimicrobiana en patógenos animales y humanos 2,5 ." (Se elimina la palabra "aunque", pues modifica el sentido de su lectura). 